\title{
Occurrence and self-management of peri-implantitis
}

\author{
Ji Su KIM, Se Hee WON, Kyung Sook HWANG*
}

Dept. of Dent. Tech., Shin Han University

\begin{abstract}
Introduction: Peri-implantitis is a destructive inflammation affecting the soft and hard tissue around dental implants. The arrangement of periodontal pathogens seen around the implant in question is very similar to various forms of periodontal disease. In particular, if the debris and tartar are not properly removed in a state of inflammation around the implant, bacteria penetrate and inflammation occurs. Later, these germs invade the implanted peri-implant tissue and cause peri-implantitis.

The main discourse: Peri-implantitis occurs in 1 in 5 implant patients. Because there is no periodontal ligament tissue in the implant, it is very difficult to detect peri-implantitis in a timely manner. Periodontal ligament tissue is a tissue that acts as a cushion between the alveolar bone and teeth in natural teeth and has anti-inflammatory action. Moreover, since implants do not have nerves in their roots, they are less sensitive to pain and susceptible to inflammation. That is, in most cases, pain is not felt even when inflammation begins or progresses. Initially, it begins as peri-implant mucositis, in which only the peri-implant becomes inflamed. Then, when the symptoms worsen, it develops into peri-implantitis. In the early stage, even with proper treatment, there is a high possibility of recovery, but if the symptoms worsen, treatment such as implant surgery or bone graft is required, and depending on the condition, it may lead to a condition that requires removal of the implant.

Conclusion: After all, since peri-implantitis is often difficult to treat once it occurs, it is important to maintain and manage the implant well before the disease develops [3]. Implant care may include removal of dead tissue during treatment, antibiotics, and improved dental hygiene. This includes mouthwash and rinsing with chlorhexidine. In addition to treatment methods, patients can easily cope with peri-implantitis by themselves. It is necessary to manage it by using dental floss once a day, using gargle twice a day, and using an interdental brush after eating three times a day. Also, you should have a habit of brushing your teeth within 1 minute after eating, brushing your teeth for more than 2 minutes, and brushing your teeth after 3 meals. In addition, regular dental visits are performed every 3-4 months for check-ups by the dentist.
\end{abstract}

Keywords: self-management, peri-implantitis, peri-implant mucositis

Acknowledgement: This study is supported by Uniance's Central Research Institute.

Copyright (C) 2021. Korean Academy of Preventive Dentistry. All rights reserved.

This is an Open Access article distributed under the terms of the Creative Commons Attribution Non-Commercial License (http://creativecommons.org/licenses/ by-nc/4.0) which permits unrestricted non-commercial use, distribution, and reproduction in any medium, provided the original work is properly cited. 